\title{
Latest Advances of LLC Converters in High Current, Fast Dynamic Response, and Wide Voltage Range Applications
}

\author{
Yang Chen and Yan-Fei Liu
}

\begin{abstract}
LLC converter has been the simplest topology since long to achieve soft switching and overall the highest performance within small form factor at converter level. This paper discusses the latest advances of LLC converter from the perspective of topology and control. The technology ranges from high current, fast dynamic response to wide operational voltage range. The application mainly falls in the scope of server and data center, and may also cover telecom, PV, battery charging, etc.
\end{abstract}

Index Terms-LLC, review, survey, current sharing, multiphase, interleave, phase shedding, passive impedance match, SR drive, fast dynamic, current mode control, current sensing, wide voltage range, hold up, high voltage gain.

\section{INTRODUCTION}

A FTER being invented for decades, LLC converter is proved as an excellent vehicle of power conversion. From the perspective of both topology and design, LLC converter is perhaps the simplest way to achieve ZVS on the primary switches (mostly MOSFETs) and ZCS on the rectifiers (eventually diodes), which respectively removes the turn on loss and the reverse recovery loss - two most urgent losses related to switching frequency. Thus, the gap ahead of the hard switching topologies is widened when the switching frequency gets higher. Yet the improvement and development is still undergoing to reform LLC converter to best fit the industry and consumer needs in different applications.

Among the various applications that LLC converter has significantly impacted, including the server and data center, telecom, PV, battery charging, etc., data center power system raises the most concern and research interest due to the existing scale of power assumption as well as the ever-increasing demand [1]. The latest survey has found that data centers consumed around $1.5 \%$ of the 270 terawatt-hours electricity usage in 2012, globally [2]. The percentage is even higher for the US at $2.2 \%$. Additionally, the energy cost of powering a typical data centers is doubled every five years [3]. It is estimated that the data center alone will consume $10 \%$ of the total electricity by 2020 [4]. Thus, large savings of electricity bill can be made by improving the efficiency and perfor-

Manuscript received Mar. 24, 2017.

The authors are with Department of Electrical and Computer Engineering, Queen's University, Kingston, ON, Canada (e-mail: yanfei.liu@queensu.ca).

Digital Object Identifier 10.24295/CPSSTPEA.2017.00007 mance of the power conversion inside the data center power system.

Wide band gap devices have made undeniable contribution to the advances of power converters in achieving high efficiency, high power density and potentially low cost when the technology becomes mature. The evolving topology and control is another propulsive force on the other wing. In this paper, the latest technologies of LLC converters in high current, fast dynamic response and wide voltage range applications will be discussed from the perspective of improving the topology and control.

The organization of this paper is as follows. Section II will discuss the performance of multiphase LLC converters and accurate driving for synchronous rectifiers. Section III will discuss technologies related to current mode control and other high level control of LLC converters to achieve fast dynamic response. Section IV will discuss the improving methods of LLC converter to meet the demands of holdup and wide voltage range operations. The paper will be concluded in Section V.

\section{Technologies for High Current Application}

It is generally believed that $100 \mathrm{~W}$ to $1 \mathrm{~kW}$ is the preferred power range for LLC converter. For lower power, which further emphasizes the simple structure and low cost, topologies like Flyback is dominant. For high power/current applications, the design becomes difficult for LLC converter. High current ripple causes high loss on the capacitor filter. And large capacitor value is needed to meet the voltage ripple requirement. Besides, the package inductance of the synchronous rectifiers (SR) introduces volt-level voltage deviation at $50 \mathrm{~A}, 500 \mathrm{kHz}$ level, which could easily trick the voltage-based gate drivers with improper timing. The layout of SRs is also difficult to achieve balanced loops and thermal performance.

\section{A. Multiphase and Current Sharing}

The issues come with the high output current could be solved by either splitting the single power train into multiple paralleled phases inside the module, or paralleling multiple phases/modules. Either way will reduce the power that each LLC phase should deal with. It should be noted that this conclusion is drawn with the assumption that current sharing 
among phases is achieved.

As an example of the split phases within single converter, [5] demonstrates a $1 \mathrm{~kW} 1 \mathrm{MHz}$ LLC converter with four phases. The conventional single transformer is separated into four small transformers. So, on the secondary side, the power train is split into four phases in parallel, with each phase dealing with a quarter of the total load power. As the primary windings are connected in series, the load current of the four phases are naturally balanced. Another highlight of this structure is that the connection point of the multiple phases could be designed at the DC side, so that the terminal loss/winding loss generated by the high frequency AC current is reduced. Similarly, $1.5 \%$ of efficiency increase is achieved by using eight phases [6].

\section{B. Interleaving}

Interleaving between phases is a desired feature on top of current sharing. The output capacitor currents stress as well as the capacitor value could be reduced at the same time. Such techniques that improve the performance and reduce the cost are most welcome to the industry. To achieve interleaving, the switching frequency of each phases must be same so to avoid beat frequency components. The primary switches must operate with $90^{\circ}\left(180^{\circ} / 2\right)$ phase shift for two phases interleaving, and $60^{\circ}\left(180^{\circ} / 3\right)$ for three phases interleaving, and so on.

The topology introduced in [7] is a straightforward demonstration of an interleaved two phase LLC converter. The input voltage is split by two capacitors and fed to the two phases in series. The output side of the two phases are connected in parallel. With this simple structure, if one phase has higher voltage gain, then that phase will provide more power to compensate the gain difference. Thus, the input capacitor of that phase will discharge more, so the input voltage of that phase will reduce, and the power transferred by that phase will also reduce. This intrinsic negative feedback generally provides good current sharing, but cannot fully remove the load current difference.

The source of the unbalanced load current is the different voltage gains between phases at given quiescent point, which is caused by the resonant components' tolerances. By employing the switch controlled capacitor (SCC), the equivalent resonant capacitor value can be controlled so to compensate the component tolerances, and thus the voltage gain difference [8], [9]. Besides, the switches always achieve ZVS, which maintains the attractiveness at high frequency applications. Fig. 1 shows the structure and waveform of a half wave SCC circuit. The equivalent capacitor value could be found as in (1).

$$
C_{S C, H W}=\frac{2 C_{a}}{2-(2 \alpha-\sin 2 \alpha) / \pi}
$$

Fig. 2 shows the topology of the two-phase SCC LLC converter. The primary switches operate with same switching frequency while out of phase for interleaving, by which the
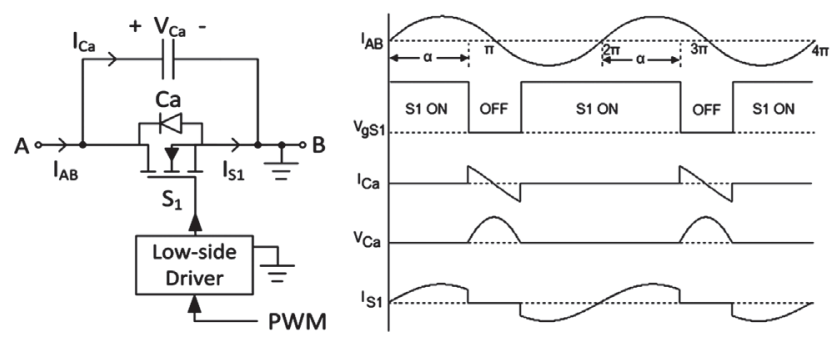

Fig. 1. Structure and waveforms of half-wave SCC circuit.

output voltage ripple is reduced by 4 times. The SCCs can actively compensate voltage gains at different frequencies, which enables accurate current sharing performance throughout the load range. It is worth mentioning that the switches of SCC are ground referenced, and of small footprint. $60 \mathrm{~V} / 2$ A MOSFETs could be used in $600 \mathrm{~W}$ application. Besides, the SCC LLC converter is able to achieve phase shedding. Thus, the light load efficiency is significantly higher than its counterparts.

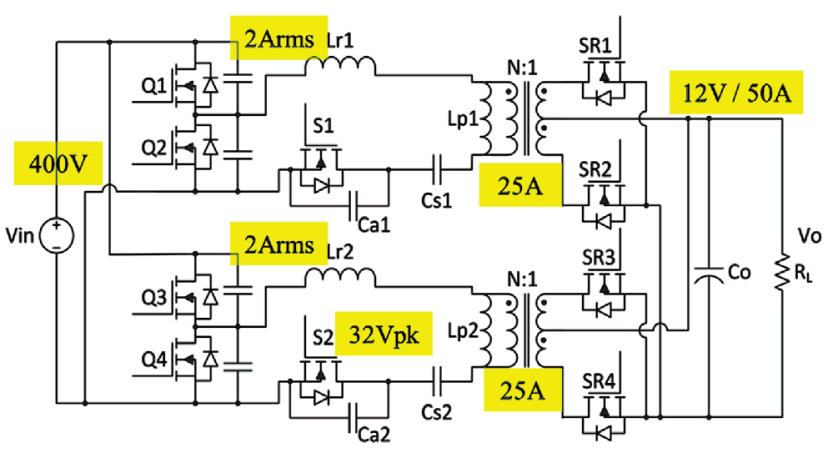

Fig. 2. Two-phase SCC LLC converter.

\section{Current Sharing with Passive Impedance Matching}

Paralleling multiple modules/phases directly at both the input side and output side are more common and practical in centralized load applications. During installation and fault, power modules could be easily cut in and out with hot swap setup. Conventional multiphase LLC converter regulates the output voltage and phase current with a current loop. The different frequencies for different phases would inevitably introduce the beat frequency ripple, and force great duty on the EMI filter. Improved methods like [7]-[13] remove most of the drawbacks but still needs the sensing and control. Comparing with these active current sharing methods, passive current sharing topologies benefits both the end user and the designer with low cost and extreme simplicity.

Fig. 3 shows the common inductor two-phase LLC converter as an example of the passive current sharing method [14], [15]. As compared to the conventional two-phase LLC converter, only a wire is added at no cost. The primary switches of the two phase operate at the same frequency to regulate the output voltage and total load current, just like conventional single phase LLC converter.

The current sharing ability is achieved by the common 


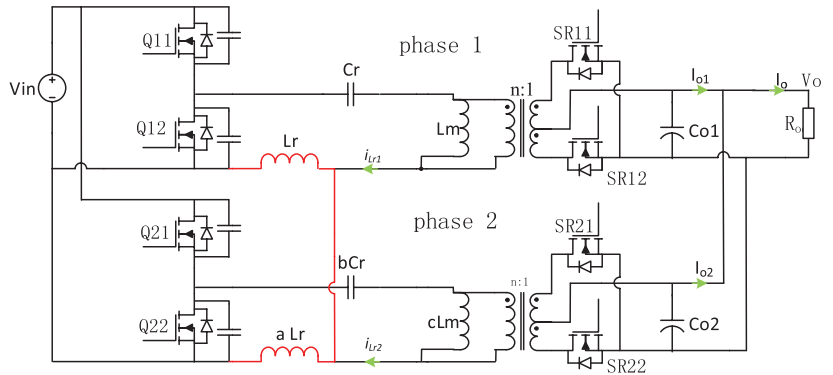

Fig. 3. Common inductor two-phase LLC converter.

inductor of the two phases, thus no additional phase current sensing or control. In conventional two-phase LLC converter without the current loop, the input square wave voltage is the same, and the transformer primary side could be viewed as a constant voltage source, which is also same for the two phases. Thus, the phase current is determined by the combined impedance of the resonant inductor and the resonant capacitor, which is close to zero around resonant frequency. Thus, a small tolerance on the components will cause very large difference. For the common inductor LLC converter, however, the phase current is determined by the resonant capacitor alone, as the inductor is shared by both phases. Consequently, the current of respective phase is nearly proportional to the capacitors' tolerance, which usually under $5 \%$. This is a perceptual understanding of the current sharing mechanism for common inductor LLC converters.

A more detailed explanation of the current sharing mechanism could be found in Fig. 4, in which the common inductor is equivalent to four components - one virtual inductor plus one virtual resistor for each phase [16]-[18].

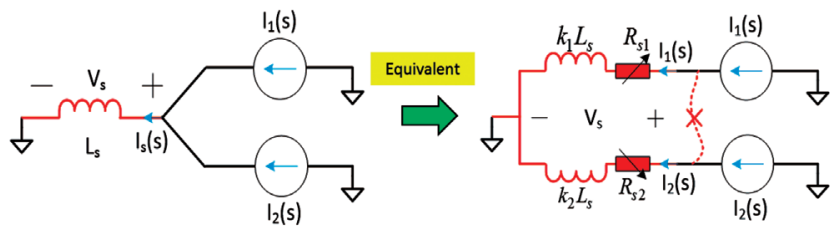

Fig. 4. Common inductor and the its equivalent model with virtual open and virtual short.

In the equivalent model, the virtual inductor and virtual resistor tanks of respective phases are independent (virtual open), which means there is no current commutation between phases. Also, the voltage cross each virtual inductor and virtual resistor tank is the same as that of the common inductor, thus the tanks are also virtual short.

At given switching frequency, (2) must hold true. Solving (2), one can find that the two virtual resistors are always of opposite sign. Whichever phase bears heavier load will have a positive virtual resistor, and the phase with lighter load will have a negative resistor. These two virtual resistors are the key to current sharing performance, as they enable a natural negative feedback - the positive resistor will decrease the power of the phase with heavy load, while the negative resistor will increase the power of the other phase with lighter load.

$$
\frac{\left(s k_{1} L_{s}+R_{s 1}\right)\left(s k_{2} L_{s}+R_{s 2}\right)}{\left(k_{1}+k_{2}\right) s L_{s}+\left(R_{s 1}+R_{s 2}\right)}=s L_{s}
$$

Fig. 5 shows the current sharing performance of the common inductor LLC converter. The two phases' current have less than $1 \%$ difference at heavy load. At light load, although phase shedding will be used in practice, the current sharing performance maintain as high.

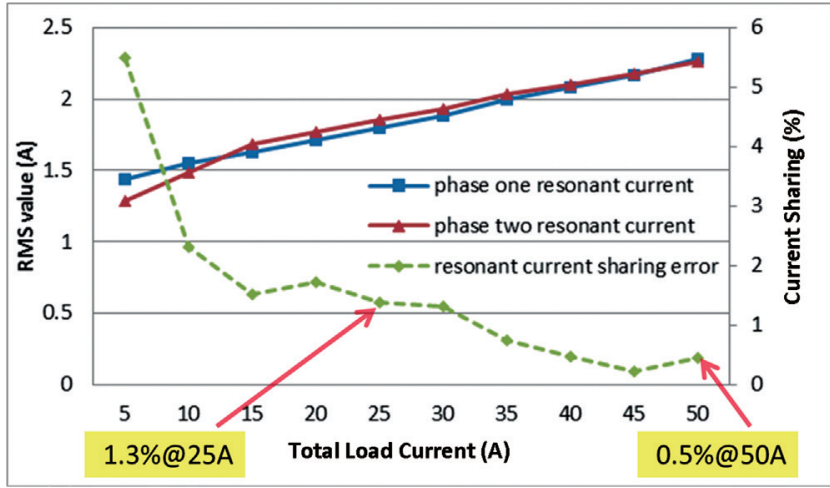

Fig. 5. Resonant current RMS value and the current sharing error

Common capacitor LLC converter has also been verified to achieve good current sharing performance [19], [20]. In addition to LLC converter, the passive impedance matching methods can also be applied to other resonant converters. More research can be done in this area.

TABLE I summarizes the features of different multiphase technologies in the high current applications.

\section{Accurate Synchronous Rectifier Driving}

The driving of synchronous rectifier is a well-known difficulty for not only LLC converters but also many other topologies, such as Flyback. Historically, many methods have been tried. Current-based methods which need current sensing transformers gradually lose the attractiveness due to the complexity and extra loss [21]-[25]. Currently, the mainstream is the voltage-based methods that detect the voltage across the drain and source of the SR to generate the driving signal.

The basic idea of the voltage-based method is to turn on the SR when $v_{D S}$ equals to the body diode conducting voltage, and turn off the SR when $v_{D S}$ comes back to zero. This holds true if only $R_{d s o n}$ is considered. However, in practice, the package and PCB track inductances will also introduce a voltage of same scale if not larger, which makes the $v_{D S}$ no longer an accurate trigger, more specifically an early trigger for turn off [26]-[28].

To obtain the accurate current information in the SR, several methods borrowed the knowledge from the conventional DCR meter, which is used to measure the DC resistor of an inductor. An elegant example of this method is the zero-crossing noise ( $\mathrm{ZCN}$ ) filter which added three passive components to achieve accurate turn on/off timing as well as diode switching 
TABLE I

Comparison of Different Multiphase Technologies

\begin{tabular}{|c|c|c|c|c|c|}
\hline Technology & Current Sharing & Cost & Complexity & Interleaving & Phase Shedding \\
\hline in-module multiphase & Good & Low & High & No & No \\
\hline split capacitor multiphase & Modest & Modest & Low & Yes & No \\
\hline SCC multiphase & Excellent & Modest & High & Yes & Yes \\
\hline conventional with current loop & Excellent & Modest & High & No & Yes \\
\hline passive impedance matching & Good & Low & Low & No & Yes \\
\hline
\end{tabular}

noise filtering [29], [30]. Fig. 6 shows the circuit of the ZCN filter.

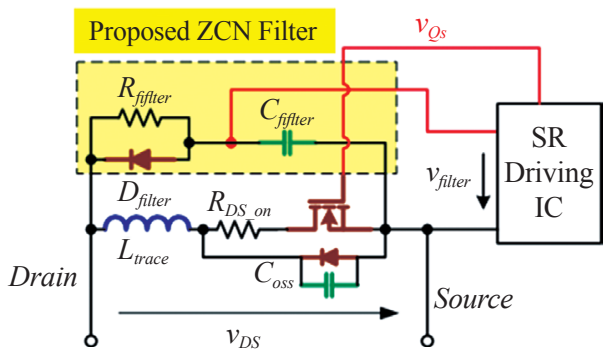

Fig. 6. The ZCN filter for SR accurate driving.

During turn on, $C_{\text {filter }}$ discharges through $D_{\text {filter }}$ together with $C_{o s s}$, thus there is not delay at turn on. Besides, the ringing of the parasitic inductors and $C_{\text {oss }}$ can be filtered during the diode switching, which avoids false turn on. During turn off, $C_{\text {filter }}$ will be charged through $R_{\text {filter }}$, so that a delay is created to compensate the early zero-crossing voltage created by the parasitic inductors. Very accurate timing could be achieved if the filter is designed so that (3) holds.

$$
\tau_{\text {filter }}=R_{\text {filter }} \cdot C_{\text {filter }}=\frac{L_{\text {trace }}}{R_{d s o n}}
$$

The ZCN filter can capture accurate switching time for SR in both transient and steady state, despite of the load current. The efficiency of a $600 \mathrm{~W}$ LLC converter could be improved by $0.8 \%$ as compared to conventional SR driving at basically no cost. This ZCN filter can also be applied to Flyback converter.

\section{Technologies for Fast Dynamic Response}

At different operation points, the LLC open-loop transfer functions vary between first order system and secondary order system, which makes the compensation difficult to optimize, hence a slow dynamic response in general.

From the experience with Buck converters, current-mode control is expected to improve the dynamic response. Different from Buck converters' current sensing, LLC converter has non-linear current shape, which is a time-domain superposition of trigonometric and triangular waveforms. Thus, the instantaneous input power cannot be easily extracted from the peak current or other instantaneous current values.

\section{A. Cycle-by-Cycle Average Current Sensing}

The average current-mode control senses the average resonant current using a current transformer and low pass filter. The compensator design is simplified as compared to voltage-mode control. However, the bandwidth is cannot be improved due to the low pass filter in the current sensing circuit. Besides, the conventional sensing method is not suitable for multiphase LLC converters that requires current sharing, because shared average current in the primary side does not necessarily guarantee good load current sharing.

Inspired by trajectory control, which reveals the relationship between resonant capacitor voltage and output current at the resonant frequency, cycle-by-cycle average current sensing method can accurately calculate the input charge at arbitrary switching frequency, based on the capacitor voltage at the turn off instant of the primary switches [31]. The relationship of the input charge and capacitor voltage is illustrated in Fig. 7.

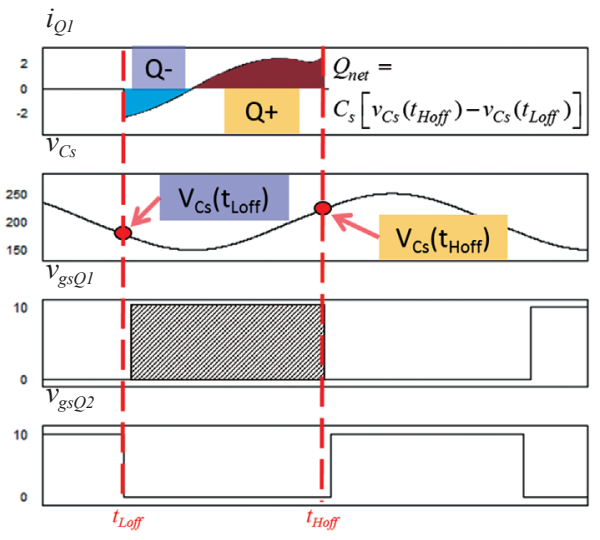

Fig. 7. Relationship of input charge and resonant capacitor voltage.

Taking advantage of the symmetry of resonant capacitor voltage, only one sensing is needed for each cycle to obtain the average current value. For half bridge LLC converter, the equation of the input average current is shown as in (4). Similar equation could be developed for full bridge LLC converter.

$$
I_{\text {in_ave }}=f_{s} C_{s}\left[2 v_{C s}\left(t_{\text {Hoff }}\right)-V_{\text {in }}\right]+2 C_{j} f_{s} V_{\text {in }}
$$

TABLE II shows the comparison of the calculated input power and the measured data. As can be observed, the cycle-by-cycle current sensing method is very accurate, despite 
TABLE II

Comparison of Measured and Calculated Input Power

\begin{tabular}{ccccc}
\hline \hline Load current & $5 \mathrm{~A}$ & $10 \mathrm{~A}$ & $15 \mathrm{~A}$ & $20 \mathrm{~A}$ \\
Actual $P_{\text {in }}$ & $71.6 \mathrm{~W}$ & $136.1 \mathrm{~W}$ & $199 \mathrm{~W}$ & $263.6 \mathrm{~W}$ \\
$v_{C S}\left(t_{\text {Loff }}\right)$ & $199.2 \mathrm{~V}$ & $188.8 \mathrm{~V}$ & $178.4 \mathrm{~V}$ & $166.4 \mathrm{~V}$ \\
$v_{C s}\left(t_{\text {Hoff }}\right)$ & $199.2 \mathrm{~V}$ & $211.2 \mathrm{~V}$ & $221.6 \mathrm{~V}$ & $233.6 \mathrm{~V}$ \\
$f_{s}$ & $199.5 \mathrm{kHz}$ & $197.3 \mathrm{kHz}$ & $197.0 \mathrm{kHz}$ & $195.5 \mathrm{kHz}$ \\
Calculated $P_{\text {in }}$ & $71.6 \mathrm{~W}$ & $135.9 \mathrm{~W}$ & $196.0 \mathrm{~W}$ & $263.6 \mathrm{~W}$ \\
Error & $0.00 \%$ & $-0.13 \%$ & $-1.50 \%$ & $-0.02 \%$ \\
\hline \hline
\end{tabular}

the load current value.

Other than current-mode control, the cycle-by-cycle average current sensing method can also be used to achieve current sharing for multiphase LLC converter. As the reference is the input charge/power rather than the resonant tank current, the current sharing performance is significantly better than the conventional current sensing method with current transformer. Fig. 8 shows the simulation comparison of the conventional method and the cycle-by-cycle average current sensing method.
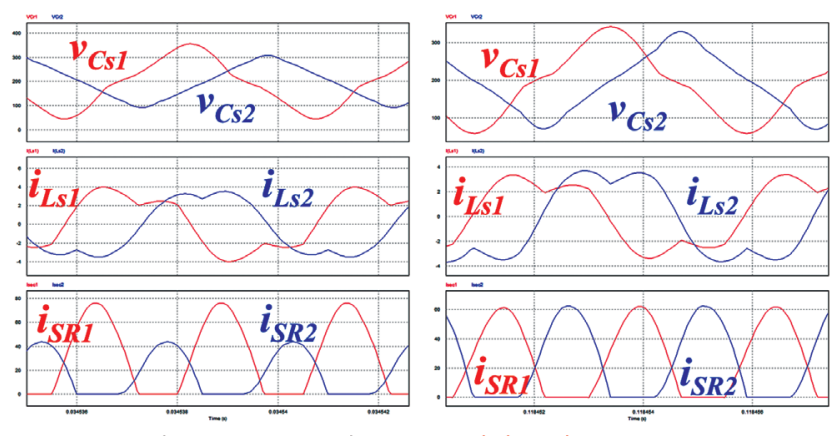

Conventional current sensing with CT

Cycle-by-cycle average current sensing

Fig. 8. Current sharing performance comparsion of conventional and cycle-by-cycle average current sensing.

\section{B. Bang Bang Charge Control for Fast Dynamic Response}

As commented previously, both voltage-mode control and conventional average current-mode control suffers from poor dynamic response performance.

The optimal trajectory control based on state-plane analysis can achieve very fast dynamic performance for series resonant converter [32]. However, when it comes to LLC converter, the extra state variable greatly increase the complexity. If fixed at resonant frequency, the simplified trajectory control can still achieve very fast dynamic performance [33]. In general, the trajectory based control requires inductor current and load current sensing, which could be complicated and lossy.

Bang Bang Charge Control (BBCC) only need to sense the resonant capacitor voltage, based on which the turn off timing of the primary switches is determined. The input power of each cycle can be then controlled directly. Thus, very fast dynamic response is achieved without complicated sensing or performance degradation [34].
The operation of LLC converter with Bang Bang Charge Control is shown in Fig. 9. The high threshold controls the turn off timing of the high side switch, and the low threshold controls the turn off timing of the low side switch. Only one of the two thresholds serve as the control variable, and the other one could be calculated based on the symmetrical waveform.

The transfer functions of both open loop and close loop are plotted in Fig. 10. As can be observed, the open loop ap-

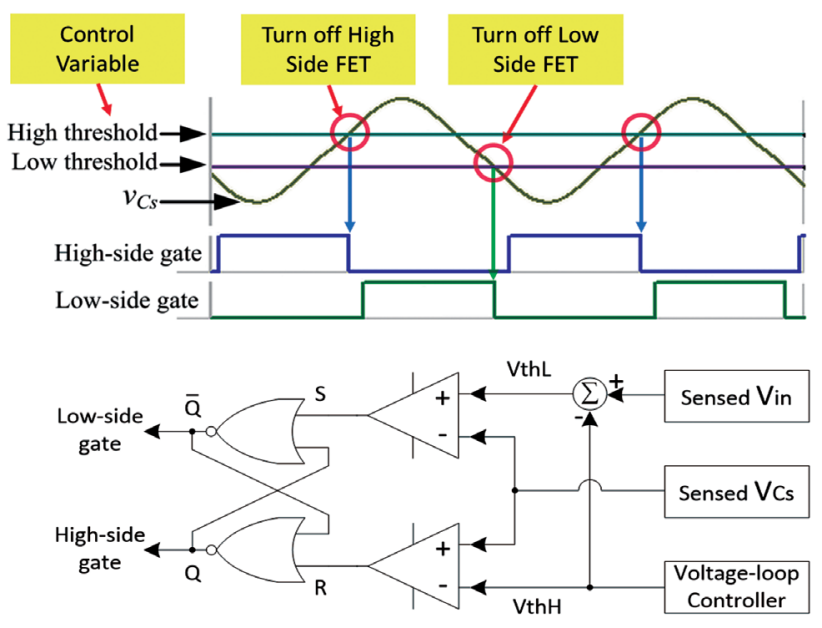

Fig. 9. Principle and operation of LLC with BBCC and the implementation.
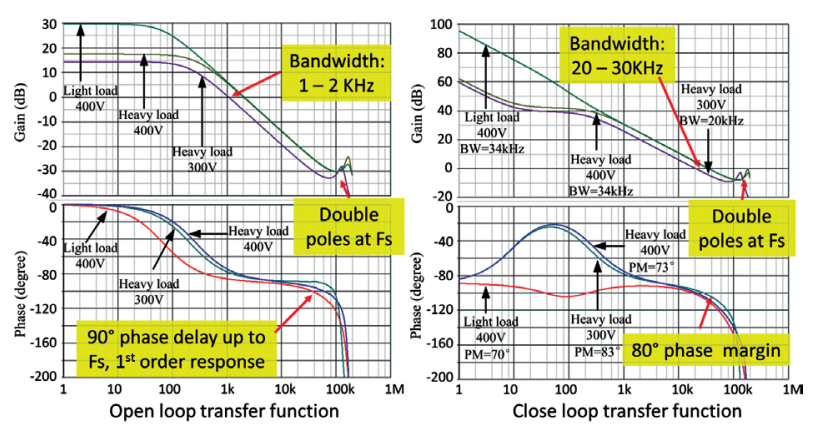

Fig. 10. Openloop and closeloop bode plot of Bang Bang Charge Control.

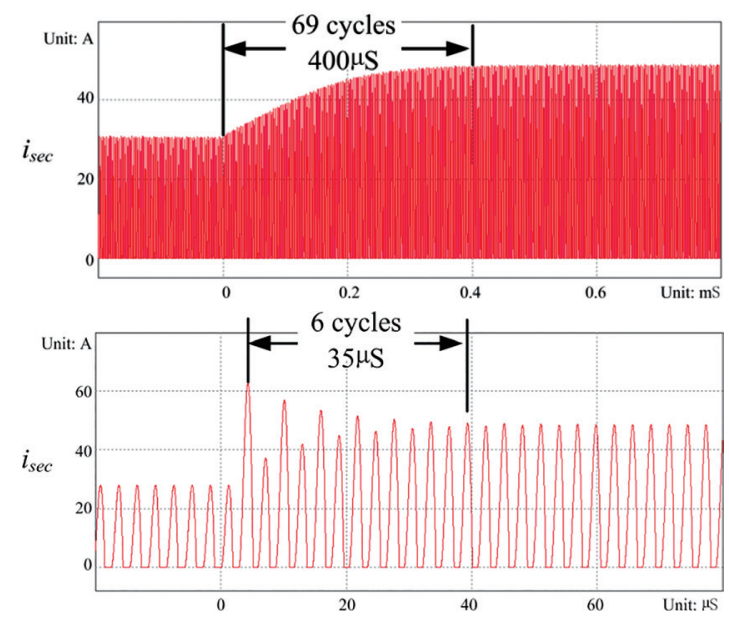

Fig. 11. 10 A to 20 A step load change of frequency control (up) and Bang Bang Charge Control (down) at $400 \mathrm{~V}$ input. 
pears as first order system, which can be easily compensated. With simple PI control, the bandwidth is improved from 1-2 $\mathrm{kHz}$ to $20-30 \mathrm{kHz}$ for different input and load conditions, which is approximately $1 / 6-1 / 5$ of the switching frequency.

Fig. 11 shows the load step response at $400 \mathrm{~V}$ input. With conventional frequency control, it takes 70 cycles or $400 \mu \mathrm{s}$ to reach steady state. While the Bang Bang Charge Control reduce it to 6 cycles, which is less than $40 \mu \mathrm{s}$.

\section{Technologies for Wide Voltage Range Application}

There are generally two types of requirement in the wide voltage range field - holdup requirement and the wide voltage range requirement itself. Although both require the LLC converter to achieve high voltage gain, the holdup application and wide voltage range application still have subtle difference in terms of requirements and solutions.

In holdup application, normally, the converter operates for long time at high input voltage. The converter only occasionally operates at low input voltage for short period, such as less than 1 second. Thus, the converter design should emphasize on the optimization at high input voltage. Design considerations for the low input voltage, e.g. thermal design, could be de-rated.

For wide voltage range application, the converter should be able to operate at the entire input voltage range for extended time. Therefore, the entire range should be optimized from both efficiency and cost point of view. The wide voltage range requirement is mandatory in many applications, such as photovoltaic and battery charging. Even in the server and data center power systems, it is becoming a more solid requirement.

\section{A. Holdup Operation}

The holdup operation is introduced and originally solved by the range winding technique [35]. The transformer has two sets of secondary windings. At normal operation, the transformer operates with the winding of small turns ratio, which is optimized. During holdup period, the winding with high turns ratio is used, such that the voltage gain is increased.

By driving the half-bridge MOSFETs with asymmetric pulse-width modulation (APWM) rather than conventional frequency modulation, LLC converter can improve voltage gain without any additional components [36]. However, the improvement relies on the parameter design.

A critical insight was revealed in [37] that if the resonant tank can be charged with more energy during one switching cycle, LLC converter achieves higher voltage gain. To charge the resonant tank more, the secondary windings are short circuit for a certain period in every switching cycle. Based on [37], a few improving methods have been proposed to adopt either Boost PWM discontinuous current mode (DCM) control [38] or phase shift control on LLC topology [39], [40]. These methods share the similar intrinsic principle with [37], but optimize the LLC converter for different specifications with respective topologies, circuits and control.

Fig. 12 shows an example of the six topologies in the sLLC converter family [41], [42]. The sLLC converter still uses center tapped transformer with synchronous rectifiers, which are commonly seen in the $12 \mathrm{~V}$ output applications.

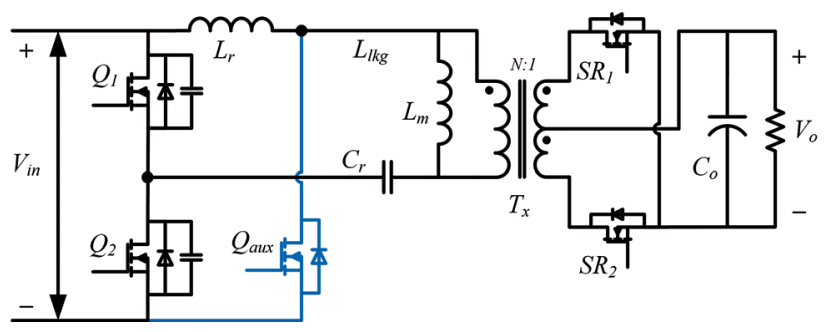

Fig. 12. sLLC converter with center-tapped transformer and SR.

The auxiliary switch remains idle at normal operation, thus the efficiency for $400 \mathrm{~V}$ operation can be optimized. During holdup period, the ground referenced auxiliary switch operates in PWM mode to energize the resonant inductor with the input voltage directly. The inductor then can store more energy in each cycle, and the converter achieves higher voltage gain. The detailed operation for $400 \mathrm{~V}$ input and $250 \mathrm{~V}$ input are illustrated in Fig. 13.
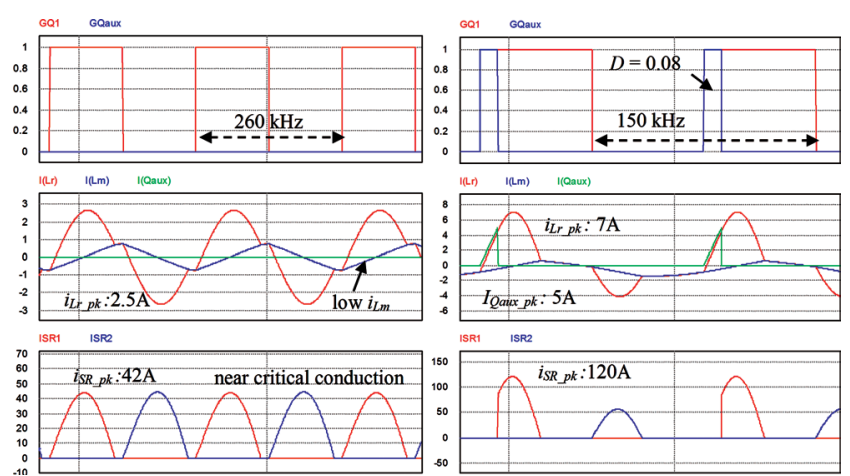

Fig. 13. sLLC converter operation with $12 \mathrm{~V} / 25 \mathrm{~A}$ load at normal input 400 $\mathrm{V}$ (left) and during holdup at $250 \mathrm{~V}$ (right).

\section{B. Wide Input Voltage Range Application}

For operation with wide input voltage range, the converter's performance and stability cannot be compromised. The methods used in the holdup application are generally not suitable due to weakened robustness.

Conventionally, a boost converter is used between the AC and the LLC stage in data center application. DC applications could also use this structure to deal with the wide input range. The method is straightforward and the control is well established [43], [44]. The downside is the complexity and cost.

By using full bridge instead of half bridge, the voltage gain of LLC converter is doubled without changing the design. Using three level branch to replace the half bridge achieves similar effect [45]. For example, if the peak voltage gain is 2 for the half bridge configuration, then the peak volt- 
age achieved by switching to full bridge is 4 . This means the allowed maximum input voltage is four times the minimum. By using two phases, the voltage range could be increased to 8 times [46]. However, with conventional frequency control, the converter operates with either half bridge or full bridge (three level) at a time, and there is no middle ground. Thus, to make use of the ZVS + ZCS region, the peak voltage gain of the resonant tank must be at least 2 times of the resonant point, which might constrain the design and efficiency in some cases.

A few improving methods use similar idea of switching between full bridge and half bridge, but make the mode switching inside each switching period [47]. Consequently, the equivalent input square wave voltage can be smoothly changed by controlling the conduction time of half bridge mode and full bridge mode (three level mode). The control can be implemented with frequency modulation, PWM, phase shift, individually or jointly, depending on the actual circuit.

Similar idea could be transferred to the secondary side. The counterparts of the half bridge and full bridge inverter are the rectifiers including the center tapped, full bridge, voltage doubler and voltage quadrupler. By switching the operation modes between them, one can achieve wide output voltage range for LLC converters [48], [49].

Another way is inspired by the LLC design requirement. From LLC converter optimal operation point of view, a large magnetizing inductor $L_{m}$ should be used at high input voltage, to limit the circulating current. While a small $L_{m}$ should be used at low input voltage, to achieve high voltage gain. This contradictory magnetizing inductor design is the limitation for LLC converter, which also implies the desired feature - an adjustable $L_{m}$ changing with the input voltage. LCLC converter can meet this requirement if designed properly [50]. The topology is shown as in Fig. 14. On the parallel branch of the resonant tank, an inductor and a capacitor is used to replace the conventional magnetizing inductor. The inductor $L_{p}$ must be external. Thus, it is more suitable for high power applications, in which integrated magnetics suffer from high conduction loss and limited window size.

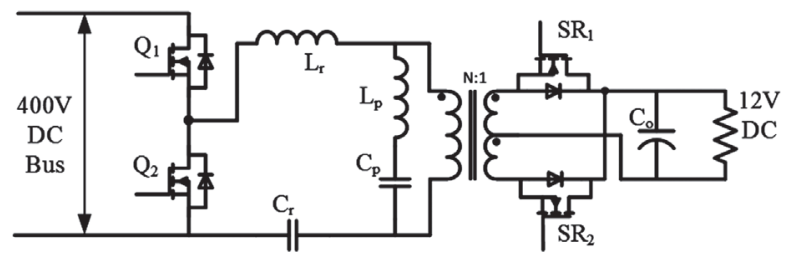

Fig. 14. LCLC converter with wide input voltage range.

By designing the total impedance of $L_{p}$ and $C_{p}$ as inductive, the LCLC converter can always be equivalent to an LLC converter for different input voltage and switching frequency. The voltage gain of LCLC converter and its equivalent LLC converter at different operation points are shown in
Fig. 15.

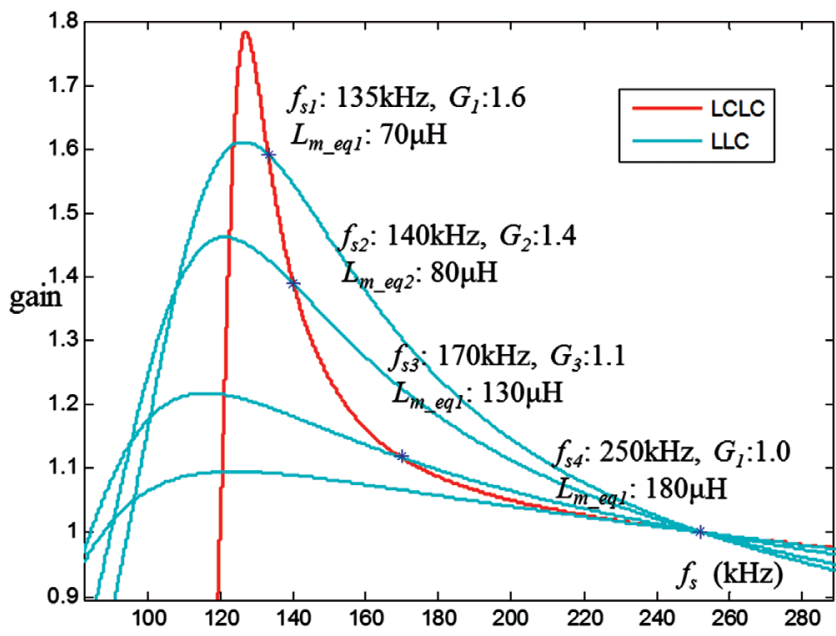

Fig. 15. Voltage gain of LCLC converter and its equivalent LLC converters .

From the bench test, LCLC converter achieves 1-2\% improvements of efficiency for different loads, as compared to an LLC converter with same $250 \mathrm{~V}-400 \mathrm{~V}$ voltage range. If compared to an LLC converter that is optimized for $400 \mathrm{~V}$, the efficiency has a $0.1-0.2 \%$ sacrifice in exchange for the much wider voltage operation range.

\section{CONCLUSION}

Three applications with significant industry value are discussed in the paper. The existing technologies are introduced and categorized. The popular technologies are explained in terms of the principle, the deriving process, and the advantages.

More in details, for high current application, SCC LLC and common inductor LLC converter are discussed and compared with existing multiphase LLC converters from the point view of current sharing performance, complexity and cost, interleaving ability, and phase shedding. The zero-crossing-noise filter is also introduced as an enabler of accurate SR driving for high current applications.

For fast dynamic application, cycle-by-cycle average current sensing reduces the complexity to the minimum, and enables both current mode control without delay and accurate current sharing for multiphase LLC converter. With bang bang charge control, the input power is controlled by turning off the primary switches at specified capacitor voltage, and achieve up to $1 / 5$ bandwidth of switching frequency.

Both holdup operation and wide voltage range applications requires high voltage gain. The subtle difference is explained and exampled. Existing methods are summarized and categorized by intrinsic principle for both applications. New topologies including sLLC for holdup operation and LCLC for wide input voltage range application are explained in details. 


\section{REFERENCE}

[1] M. Dayarathna, Y. Wen, and R. Fan, "Data center energy consumption modeling: A survey," IEEE Commun. Surv. Tutorials, vol. 18, no. 1, pp. 732-794, 2016.

[2] W. Van Heddeghem, S. Lambert, B. Lannoo, D. Colle, M. Pickavet, and P. Demeester, "Trends in worldwide ICT electricity consumption from 2007 to 2012," Comput. Commun., vol. 50, pp. 64-76, Sep. 2014.

[3] R. Buyya, C. Vecchiola, and S. T. Selvi, Mastering cloud computing: foundations and applications programming. Morgan Kaufmann, 2013.

[4] F. C. Lee, Q. Li, Z. Liu, Y. Yuchen, C. Fei, and M. Mu, "Application of GaN devices for $1 \mathrm{~kW}$ server power supply with integrated magnetics," CPSS TPEA, vol. 1, no. 1, pp. 3-12, 2016.

[5] D. Huang, S. Ji, and F. C. Lee, "LLC resonant converter with matrix transformer," IEEE Trans. Power Electron., vol. 29, no. 8, pp. 43394347, Aug. 2014

[6] M. Mu and F. Lee, "Design and optimization of a 380V-12V high-frequency, high-current LLC converter with GaN devices and planar matrix transformers," IEEE J. Emerg. Sel. Top. Power Electron., vol. 4, no. 3, pp. 854-862, 2016.

[7] B.-C. Kim, K.-B. Park, C.-E. Kim, and G.-W. Moon, "Load sharing characteristic of two-phase interleaved LLC resonant converter with parallel and series input structure," Energy Conversion Congress and Exposition, 2009. ECCE 2009. IEEE. pp. 750-753, 2009.

[8] Z. Hu, Y. Qiu, L. Wang, and Y. -F. Liu, "An Interleaved LLC Resonant Converter Operating at Constant Switching Frequency," Power Electronics, IEEE Transactions on, vol. 29, no. 6. pp. 2931-2943, 2014.

[9] Z. Hu, Y. Qiu, Y.-F. Liu, and P. C. Sen, "A control strategy and design method for interleaved LLC converters operating at variable Switching Frequency," Power Electronics, IEEE Transactions on, vol. 29, no. 8. pp. 4426-4437, 2014.

[10] Z. Hu, Y. Qiu, L. Wang, and Y. -F. Liu, "An interleaved LLC resonant converter operating at constant switching frequency," in 2012 IEEE Energy Conversion Congress and Exposition (ECCE), 2012, pp. 3541-3548.

[11] E. Orietti, P. Mattavelli, G. Spiazzi, C. Adragna, and G. Gattavari, "Two-phase interleaved LLC resonant converter with current-controlled inductor," Power Electronics Conference, 2009. COBEP '09. Brazilian, 2009, pp. 298-304.

[12] E. Orietti, P. Mattavelli, G. Spiazzi, C. Adragna, and G. Gattavari, "Analysis of multi-phase LLC resonant converters," Power Electronics Conference, 2009. COBEP '09. Brazilian, 2009, pp. 464-471.

[13] H. Figge, T. Grote, N. Froehleke, J. Boecker, and P. Ide, "Paralleling of LLC resonant converters using frequency controlled current balancing," in 2008 IEEE Power Electronics Specialists Conference, 2008, pp. 1080-1085.

[14] H. Wang, Y. Chen, Y. -F. Liu, J. Afsharian, and Z. Yang, "A passive current sharing method with common inductor multi-phase LLC resonant converter," IEEE Trans. Power Electron., Early Access, 2016.

[15] H. Wang, Y. Chen, Y. -F. Liu, J. Afsharian, and Z. A. Yang, "A common inductor multi-phase LLC resonant converter," in 2015 IEEE Energy Conversion Congress and Exposition (ECCE), 2015, pp. 548-555.

[16] H. Wang, Y. Chen, and Y.-F. Liu, "A passive-impedance-matching technology to achieve automatic current sharing for multi-phase resonant converter," IEEE Trans. Power Electron., Early Access, 2017.

[17] H. Wang, Y. Chen, Z. Hu, L. Wang, T. Liu, W. Liu, Y. -F. Liu, J. Afsharian, and Z. Yang, "An algorithm to analyze circulating current for multi-phase resonant converter," in 2016 IEEE Applied Power Electronics Conference and Exposition (APEC), 2016, pp. 899-906.

[18] H. Wang, Y. Chen, Y. -F. Liu, and S. Liu, "Automatic current-sharing method for multi-phase LLC resonant converter," in 2016 IEEE 8th International Power Electronics and Motion Control Conference (IPEMC-ECCE Asia), 2016, pp. 3198-3205.

[19] H. Wang, Y. Chen, Y. Qiu, P. Fang, Y. Zhang, L. Wang, Y. -F. Liu, J. Afsharian, and Z. Yang, "A common capacitor multi-phase LLC converter with passive current sharing ability," IEEE Trans. Power Electron., Early Access, 2017.

[20] H. Wang, Y. Chen, Z. Hu, L. Wang, Y. Qiu, W. Liu, Y. -F. Liu, J. Afsharian, and Z. Yang, "A common capacitor multi-phase LLC resonant converter," in 2016 IEEE Applied Power Electronics Conference and Exposition (APEC), 2016, pp. 2320-2327.

[21] B. Yuan, M. Xu, X. Yang, and D. Li, "A new structure of LLC with primary current driven synchronous rectifier," in 2009 IEEE 6th International Power Electronics and Motion Control Conference, 2009, pp. 1266-1269.

[22] G. Zhang, J. Zhang, Z. Chen, X. Wu, and Z. Qian, "LLC resonant DC/DC converter with current-driven synchronized voltage-doubler rectifier," in 2009 IEEE Energy Conversion Congress and Exposition, 2009, pp. 744-749.

[23] X. Wu, G. Hua, J. Zhang, and Z. Qian, "A new current-driven synchronous rectifier for series-Parallel resonant (LLC) DC-DC converter," IEEE Trans. Ind. Electron., vol. 58, no. 1, pp. 289-297, Jan. 2011.

[24] C. Zhao, B. Li, J. Cao, Y. Chen, X. Wu, and Z. Qian, "A novel primary current detecting concept for synchronous rectified LLC resonant converter," in 2009 IEEE Energy Conversion Congress and Exposition, 2009, pp. 766-770.

[25] J. Liao, J. Wang, J. Zhang, and Z. Qian, "A novel current driving scheme for LLC resonant converter with synchronized voltage-doubler rectifier," in 2011 Twenty-Sixth Annual IEEE Applied Power Electronics Conference and Exposition (APEC), 2011, pp. 566-570.

[26] D. Fu, Y. Liu, F. C. Lee, and M. Xu, "A novel driving scheme for synchronous rectifiers in LLC resonant converters," IEEE Trans. Power Electron., vol. 24, no. 5, pp. 1321-1329, May 2009.

[27] D. Fu, B. Lu, and F. C. Lee, "1MHz high efficiency LLC resonant converters with synchronous rectifier," in 2007 IEEE Power Electronics Specialists Conference, 2007, pp. 2404-2410.

[28] D. Fu, Y. Liu, F. C. Lee, and M. Xu, "An improved novel driving scheme of synchronous rectifiers for LLC resonant converters," in 2008 Twenty-Third Annual IEEE Applied Power Electronics Conference and Exposition, 2008, pp. 510-516.

[29] D. Wang and Y. -F. Liu, "A zero-crossing noise filter for driving synchronous rectifiers of LLC resonant converter," IEEE Trans. Power Electron., vol. 29, no. 4, pp. 1953-1965, Apr. 2014.

[30] D. Wang, L. Jia, J. Fu, Y. -F. Liu, and P. C. Sen, "A new driving method for synchronous rectifiers of LLC resonant converter with zero-crossing noise filter," in 2010 IEEE Energy Conversion Congress and Exposition, 2010, pp. 249-255.

[31] Z. Hu, Y. -F. Liu, and P. C. Sen, "Cycle-by-cycle average input current sensing method for LLC resonant topologies," Energy Conversion Congress and Exposition (ECCE), 2013 IEEE, 2013, pp. 167174

[32] R. Oruganti, J. J. Yang, and F. C. Lee, "Implementation of optimal trajectory control of series resonant converter," IEEE Trans. Power Electron., vol. 3, no. 3, pp. 318-327, Jul. 1988.

[33] W. Feng, F. C. Lee, and P. Mattavelli, "Simplified optimal trajectory control (SOTC) for LLC resonant converters," IEEE Trans. Power Electron., vol. 28, no. 5, pp. 2415-2426, May 2013.

[34] Z. Hu, Y. -F. Liu, and P. C. Sen, "Bang-Bang Charge Control for LLC resonant converters," IEEE Trans. Power Electron., vol. 30, no. 2, pp. 1093-1108, Feb. 2015.

[35] B. Yang, P. Xu, and F. C. Lee, "Range winding for wide input range front end DC/DC converter," APEC 2001. Sixt. Annu. IEEE Appl. Power Electron. Conf. Expo., vol. 1, 2001, pp. 476-479.

[36] B. Kim, S. Member, K. Park, and G. Moon, "Asymmetric PWM control scheme during hold-up Ttime for LLC resonant converter," IEEE Trans. Ind. Electron., vol. 59, no. 7, pp. 2992-2997, 2012.

[37] B.-C. Kim, K.-B. Park, S.-W. Choi, and G.-W. Moon, "LLC series resonant converter with auxiliary circuit for hold-up time," INTELEC 2009 - 31st Int. Telecommun. Energy Conf., Oct. 2009, pp. $1-4$, Oct. .

[38] I. H. Cho, Y. Do Kim, and G. W. Moon, "A half-bridge LLC resonant converter adopting boost PWM control scheme for hold-up state operation," IEEE Trans. Power Electron., vol. 29, no. 2, pp. 841-850, Feb. 2014

[39] J. W. Kim and G. W. Moon, "A new LLC series resonant converter 
with a narrow switching frequency variation and reduced conduction losses," IEEE Trans. Power Electron., vol. 29, no. 8, pp. 4278-4287, 2014.

[40] H. Wu, T. Mu, X. Gao, and Y. Xing, "A secondary-side phase-shiftcontrolled LLC resonant converter with reduced conduction loss at normal operation for hold-up time compensation application," Power Electron. IEEE Trans., vol. 30, no. 10, pp. 5352-5357, 2015.

[41] H. Wang, Y. Chen, P. Fang, Y.-F. Liu, J. Afsharian, and Z. Yang, “An LLC converter family with auxiliary switch for hold-up mode operation," IEEE Trans. Power Electron., vol. 32, no. 6, pp. 4291-4306, Jun. 2017.

[42] H. Wang, Y. Chen, Y.-F. Liu, J. Afsharian, and Z. Yang, “A new LLC converter family with synchronous rectifier to increase voltage gain for hold-up application," Energy Convers. Congr. Expo. (ECCE), 2015 IEEE, 2015, pp. 5447-5453.

[43] F. Musavi, M. Craciun, D. S. Gautam, W. Eberle, and W. G. Dunford, "An LLC resonant DC-DC converter for wide output voltage range battery charging applications," IEEE Trans. Power Electron., vol. 28 , no. 12 , pp. 5437-5445, Dec. 2013.

[44] H. Wang, S. Dusmez, and A. Khaligh, "Design and analysis of a fullbridge LLC-based PEV charger optimized for wide battery voltage range," IEEE Trans. Veh. Technol., vol. 63, no. 4, pp. 1603-1613, May 2014.

[45] W. Inam, K. K. Afridi, and D. J. Perreault, "Variable frequency multiplier technique for high-efficiency conversion over a wide operating range," IEEE J. Emerg. Sel. Top. Power Electron., vol. 4, no. 2, pp. 335-343, Jun. 2016.

[46] H. Hu, X. Fang, S. Member, and F. Chen, "A modified high-efficiency LLC converter with two transformers for wide input voltage range applications," IEEE Trans. POWER Electron., vol. 28, no. 4, pp. 1946-1960, 2013.

[47] X. Sun, X. Li, Y. Shen, B. Wang, and X. Guo, "Dual-bridge LLC resonant converter with fixed-frequency PWM control for wide input applications," IEEE Trans. Power Electron., vol. 32, no. 1, pp. 6980, Jan. 2017.

[48] H. Wu, X. Zhan, and Y. Xing, "Interleaved LLC resonant converter with hybrid rectifier and variable-frequency plus phase-shift control for wide output voltage range applications," IEEE Trans. Power Electron., vol. 32, no. 6, pp. 4246-4257, Jun. 2017.

[49] H. Wu, Y. Li, and Y. Xing, "LLC resonant converter with semiactive variable-structure rectifier (SA-VSR) for wide output voltage range application," IEEE Trans. Power Electron., vol. 31, no. 5, pp. 33893394, May 2016.

[50] Y. Chen, H. Wang, Z. Hu, Y. -F. Liu, J. Afsharian, and Z. Yang, "LCLC resonant converter for hold up mode operation," Energy Conversion Congress and Exposition (ECCE), 2015 IEEE. pp. 556562, 2015.

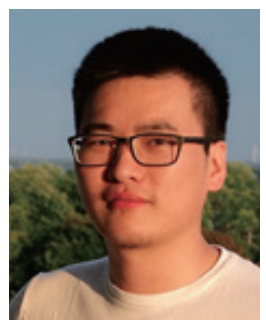

Yang Chen received his B.Sc. degree in 2011, his M.Sc. degree in 2013, both in electrical engineering, from Beijing Institute of Technology, Beijing, China. He is currently working toward the Ph.D. degree at Queen's University, Kingston, Canada. His primary research interest is to improve the topology, control, and design of resonant converters in various applications ranging from $10 \mathrm{~W}$ to $1 \mathrm{~kW}$ with high efficiency, simple solution, low cost and small form factor. His other research interest includes power factor correction technology and digital control

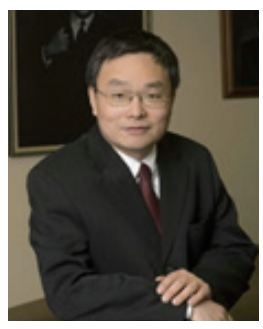

Yan-Fei Liu Dr. Liu received his Bachelor and Master degree from the Department of Electrical Engineering from Zhejiang University, China, in 1984 and 1987 and $\mathrm{PhD}$ degree from the Department of Electrical and Computer Engineering, Queen's University, Kingston, ON, Canada, in 1994

He was a Technical Advisor with the Advanced Power System Division, Nortel Networks, in Ottawa, Canada from 1994 to 1999 . Since 1999, he has been with Queen's University, where he is currently a Professor with the Department of Electrical and Computer Engineering. His current research interests include digital control technologies for high efficiency, fast dynamic response dc-dc switching converter and ac-dc converter with power factor correction, resonant converters and server power supplies, and LED drivers. He has authored over 200 technical papers in the IEEE Transactions and conferences, and holds 20 U.S. patents. He is also a Principal Contributor for two IEEE standards. He received Premier's Research Excellence Award in 2000 in Ontario, Canada. He also received the Award of Excellence in Technology in Nortel in 1997.

Dr. Liu serves as an Editor of IEEE Journal of Emerging and Selected Topics of Power Electronics (IEEE JESTPE) since 2013, an associate Editor for IEEE Transactions on Power Electronics since 2001, and a Guest Editor-in-Chief for the special issue of Power Supply on Chip of IEEE Transactions on Power Electronics from 2011 to 2013. He also served as Guest Editor for special issues of JESTPE: Miniaturization of Power Electronics Systems in 2014 and Green Power Supplies in 2016. He serves as Co-General Chair of ECCE 2015 held in Montreal, Canada, in September 2015. He will be the General chair of ECCE 2019 to be held in Baltimore, USA. He has been the chair of PELS Technical Committee on Control and Modeling Core Technologies since 2013 and chair of PELS Technical Committee on Power Conversion Systems and Components from 2009 to 2012. 